kürzere Zeit bestanden hatte, ihren Ursprung verdankt. Es ist wahrscheinlich, dass die extraperitonealen Haematokelen geringeren Umfanges häufiger vorkommen und in der Geschichte der Haematokele intraperitonealis eine grössere Rolle spielen, als vermuthet wird.

\title{
Uterus unicornis dexter
}

mit eigenthümlichem Verlaufe der Tuba und des Ovariums links.

\section{Von}

\section{Dr. Herman Beigel}

in Wien.

(Mit einer Abbildung, Tafel XI., Fig. 3.)

Das interessante Präparat, welches den Gegenstand dieser Mittheilung bilden soll, ist mir von Herrn Dr. Zuckerkandl, Assistenten des hiesigen anatomischen Institutes, freundlichst zur Verfügung gestellt worden, wofür ich ihm hiermit meinen Dank ausspreche. Es rührt von einem neugeborenen Kinde her, welches einige Tage nach der Geburt gestorben ist, und in dessen Körper sich anderweitige Bildungsanomalien nicht vorgefunden haben. Da ich eine Anomalie, wie sie an dem vorliegenden Präparate wahrnehmbar ist, weder in Kussmaul's bekanntem Werke von, „dem Mangel, der Verkümmerung und Verdoppelung der Gebärmutter", noch in Livius Fïrst's schöner Arbeit ,über Bildungshemmungen des Utero-Vaginalkanales" 1 ) gefunden habe, halte ich den Fall wohl der Mittheilung werth. Derselbe stellt ein exqujsites Exemplar eines Uterus unicornis dexter dar. Das Horn $(U)$, von dessen Spitze die Tuba $(T)$ mit dahinterliegendem, wohlgebildeten Ovarium $(O)$ abgeht, während der Ursprung des Ligamentum rotundum weiter unten erfolgt, neigt sich, wie es ja immer der Fall, nach rechts, und zeigt im oberen Abschnitte jene Krümmung, wie sie bei normal entwickelten Kinderuteris fast regelmässig angetroffen wird. Die Entwickelung ist in unserem Falle derart, dass man diesem Abschnitte es kaum anmerkt, dass er einem unicor-

1) Mittheilungen über die Thätigkeit aus den Verhandlungen der Gesellsehaft für Geburtshülfe zu Leipzig, in der Monatsschrift für Geburtskunde und Frauenkrankheiten 1867, Band XXX, Heft 2 u. 3. 
nen Organe angehört. Die in Millimetern gegebenen Maassverhältnisse erweisen sich wie folgt:

1) Gesammtlänge des Uterus 30.

2) Länge des Körpers (d. h. vom Fundus bis zur Knickungsstelle) 6.

3) Länge des Halses (von der Knickungsstelle bis zum äusseren Muttermunde) 18.

4) Breite des Hornes am Fundus 4 .

5) Länge des Os externum 2.

6) Dicke des Corpus (unterhalb der Knickungsstelle) 6 .

7) Dicke der vorderen Wand:

a) am Fundus 2,5 .

b) am Corpus 2,5 .

c) an der Cervix 5 .

8) Dicke der hinteren Wand:

a) am Fundus 3.

b) am Corpus 4 .

c) an der Cervix 7 .

9) Dicke des Fundusdaches 4.

10) Länge der vorderen Lippe 6.

11) Dicke der vorderen Lippe 3,5 .

12) Länge der hinteren Lippe 6,5 .

13) Dicke der hinteren Lippe 6.

14) Länge der Vagina 28.

15) Breite der Vagina 8.

Die äusseren Geschlechtstheile befinden sich in vollkommen normalem Zustande. Die rechte Tube entspringt, wie bemerkt, an der Spitze des kegelförmigen Hornes und misst $25 \mathrm{Mm}$. in der Länge; ihr Verhältniss zum breịten Mutterbande, sowie zu dem Ovarium bietet nichts Ungewöhnliches dar. Das rechte Ovarium ist $12 \mathrm{Mm}$. lang, 4,5 breit und 1,5 dick. Das runde Mutterband nimmt seinen Ursprung unmittelbar unterhalb des Ligámentum ovarii.

Eigenthümlich gestalten sich die Verhältnisse der linken Seite. Von einem Horne ist keine Andeutung vorhanden. Hingegen geht $13 \mathrm{Mm}$. unterhalb der Spitze des rechten Hornes ein 1 bis 1,5 Mm. starker Strang ab, begiebt sich an die vordere Bauchwand und muss wohl als das linke runde Ligament angesehen werden. Nachdem dieser Strang $(G)$ einen Weg von $16 \mathrm{Mm}$. in transversaler Richtung zurïckgelegt hat, dort, wo er umbiegt, um sich nach vorn zu begeben $(X)$, gewinnt er etwa das Doppelte seiner früheren Stärke, denn hier findet die Vereinigung mit einem anderen Strange statt $(E)$, welcher von hinten und oben am Peritoneum, längs des Musculus iliacus sinister herabsteigt und von seinem Ursprunge $(H)$ bis zur Vereinigungsstelle $(X) 39$ Millimeter misst. Dieser in seinem unteren Abschnitte wenigor verständliche Strang zeigt sich an seiner Ursprungsstelle oder besser an seinem Ende als die linke Tuba. $A$ ist ein blasenförmiger Anhang, $B$ eine mit Fimbrien besetzte Platte und $C$ eine Morgagnische Hydatide. Es fragt sich demnach 
nur, ob jener Absehnitt, welcher von $X$ bis an das rechte Horn reicht, dieser Tuba oder dem Ligamentum rotundum zuzusprechen sei. Die mikroskopische Untersuchung könnte hierüber wohl Klarheit verschaffen, doch habe ich diese unterlassen, da ich das Präparat für die Sammlung möglichst vollständig erhalten wollte.

Diese Tuba ist übrigens ihrer ganzen Länge nach am Peritoneum festgelöthet, ihre äusserste Extremität $(H)$ ist von der Spitze des rechten Hornes $48 \mathrm{Mm}$. entfernt. Vor der Tuba liegt von $H$ bis $L$ in einer Länge von $18 \mathrm{Mm}$. ein Körper, dessen oberes Ende 2,5 $\mathrm{Mm}$., dessen unteres Ende nur 0,5 Mm. misst, in seiner unteren Fläche gleichfalls an das Peritoneum geheftet ist und den Eindruck eines Ovarium machte. Diese Vermuthung wurde durch die mikroskopische Untersuchung vollkommen bestätigt, das Gewebe erweist sich als Ovarialstroma mit normalen Eiern.

Die Vorgänge, welche zur gänzlichen oder theilweisen einseitigen Ausbildung eines Generationsabschnittes führen, sind bekannt. Welche fötalen Processe aber stattgehabt haben müssen, um neben der Verkümmerung der einen Uterushälfte noch das Ovarium und die Tuba an der verkümmerten Seite weit weg von ihrer normalen Lage zu führen, um sie daselbst mit dem Peritoneum. zu vereinigen, lässt sich kaum vermuthen.

Schliesslich möchte ich nur noch darauf hinweisen, dass die von mir hier gegebenen Maasse mit denjenigen der Abbildung darum nicht durchweg übereinstimmen, weil diese im frischen Zustande angefertigt ward, die Messung hingegen von mir erst später, und nachdem das Präparat längere Zeit in Spiritus gelegen, vorgenommen worden ist.

\section{Erklärung der Abbildung.}

$V$ - Harnblase. $R$ - Rectum. $F$ - injicirte Gefässe. $U-$ rechtes Uterushorn. $T$ - rechte Tuba. $O$ - rechtes Ovarium. $U r$ - linker Ureter. $G$-Strang, vom rechten Horne abgehend (Tuba oder Ligamentum rotundum?). $T^{\prime}$ - linke Tuba. $X$-Vereinigung derselben mit dem nach der vorderen Bauchwand verlaufenden Ligamentum rotundum. $L D$ - linkes Ovarium. $A-$ Blasenförmiger Anhang an der linken Tuba. $B$ - flacher mit Fimbrien besetzter Anhang. $\quad C-$ Morgagnische Hydatide. 